\title{
Physical and chemical properties of soil at Rajgurunagar (Khed) Tehsil, Pune (MS) India Hrishikesh Khodade
}

Department of Botany, S. M. Joshi College, HADAPSAR, PUNE (MS), INDIA E-mail : rishikesh@live.in

Received : 25.02.2020; Accepted : 22.04.2020

\begin{abstract}
Soil plays an important role for sustainable agricultural development which is a widely accepted fact. The composition of soil makes perfect recipe for proper growth and development of growing plants. Mainly the texture and contains of the soil give an idea about overall productivity of any type of soil. The present case study was conducted on the physical and chemical properties of soil at Rajgurunagar (Khed) Tehsil, Pune District (Maharashtra) state of India. The study has been conducted in 5 different localities of different directions for better understanding of nature and composition of soil. Rajgurunagar(Khed) is well known for upcoming developing region due to accumulation of various industrial companies such as SEZ, MIDC and many more. The effect of industrialisation on hydrosphere, atmosphere and lithosphere is noticeable in this Tehsil as an effect is seen on plant growth and development and is affecting on abundance, density of many plant as well as animal species. The total land area is unmanageable for agricultural development purpose. The impact of environmental factors on the soil attributes such as soil particle size which are the product of high degree of soil pollutants, organic matter content which show variability at different localities and other chemical constituents which indicate high degree of salt presence. The control measures are also indicated in a given study to overcome challenging and problem associated conditions.

Figure : 00

References : 19

Tables : 03

KEY WORDS : Abundance, Density, Industrialisation, Localities, Productivity, Sustainable,
\end{abstract}

\section{Introduction}

Rajgurunagar is getting transformed from agriculture based Tehsil to industrial and more civilised Tehsil. Various types of agricultural production have been practiced in this Tehsil as a part of culture, but advancement in industrialisation is affecting various abiotic components and among various abiotic factors mainly soil quality which is considered as a key element of sustainable agriculture ${ }^{18}$. Lithosphere's biogeochemical diversity is important aspect for understanding the improvement in agricultural sectors. Soil consists various types of chemicals, physical and biological matter. As the soil particles are providing the surface area for adhesion of organic and inorganic matter, thus the quality of soil depends on a type of organic matter and inorganic ions it consists. Awareness among the people was raised when the National Academy of Sciences published 'Soil and Water Quality: An Agenda for Agriculture'14. The growth of plant is completely dependent on soil texture, nutrient content of soil and soil microbial flora. Soil $\mathrm{pH}$, soil water holding capacity and soil conductivity are the major parameters which were needed to be considered.
Increasing awareness regarding soil health and quality resources is important to evaluate as soil is not only the component of biosphere but also a part of maintenance of local, regional and global environmental quality ${ }^{7}$. The assessment of soil quality or health and direction of change with time, is the primary indicator of sustainable land management ${ }^{10}$. The indicators of soil quality which are selected are inexpensive to measure ${ }^{9}$. The concept of soil quality has been suggested by several authors ${ }^{6,11,16,17}$ as a tool for assessing long-term sustainability of agricultural practices at local, regional, national, and international levels. There have been introduced the concept of minimum data, as a combination of physical, chemical and biological indicators for soil quality assessment ${ }^{12}$. In this paper we have studied and examined the physical and chemical constituents which are present in the soil at Rajgurunagar. Total land covered by Rajgurunagar is $5,500 / \mathrm{km}^{2}$ and consists many towns in it. The Rajgurunagar Tehsil is located Latitude: $18.86^{0} \mathrm{~N}$, Longitude: $73.900^{\circ} \mathrm{E}$ and of altitude $645 \mathrm{Metre}$ from sea level. Rajgurunagar is situated on Pune- Nashik highway alongside and comprises Ale (North) to Bhor (South) and 
TABLE-1 : Soil samples from different localities

\begin{tabular}{|c|c|c|c|c|c|c|c|c|c|c|c|c|c|}
\hline \multirow{4}{*}{$\begin{array}{l}\text { Sr. } \\
\\
1\end{array}$} & \multirow{4}{*}{\begin{tabular}{|l} 
Location \\
\\
Kadus \\
\end{tabular}} & \multicolumn{12}{|c|}{ Particle size range } \\
\hline & & \multicolumn{4}{|c|}{ Sandy } & \multicolumn{4}{|c|}{ Stilt } & \multicolumn{4}{|c|}{ Clay } \\
\hline & & \multicolumn{3}{|c|}{$200-50 \mu \mathrm{m} \%$} & \multirow{2}{*}{$\frac{\text { Avg \% }}{19}$} & \multicolumn{3}{|c|}{$2-50 \mu \mathrm{m} \%$} & \multirow{2}{*}{$\begin{array}{c}\text { Avg\% } \\
74\end{array}$} & \multicolumn{3}{|c|}{$<2 \mu \mathrm{m} \%$} & \multirow{2}{*}{$\begin{array}{c}\text { Avg\% } \\
07\end{array}$} \\
\hline & & 19 & 18 & 19 & & 70 & 74 & 74 & & 06 & 08 & 06 & \\
\hline 2 & Bordara & 10 & 11 & 11 & 11 & 79 & 79 & 72 & 79 & 10 & 11 & 10 & 10 \\
\hline 3 & Peth & 18 & 18 & 17 & 18 & 75 & 74 & 74 & 74 & 10 & 08 & 08 & 08 \\
\hline 4 & Rajgurunagar (Khed) & 10 & 11 & 10 & 10 & 70 & 75 & 75 & 75 & 12 & 15 & 15 & 15 \\
\hline 5 & Kanhersar & 20 & 21 & 20 & 20 & 60 & 64 & 60 & 60 & 20 & 21 & 20 & 20 \\
\hline
\end{tabular}

Lonawala (West) to Indapur (East).

As the Rajgurunagar (Khed) Tehsil is surrounded by such habitat conditions which have created a threat to vegetation and survival of many species, the Industrial zone is responsible of variability in soil chemical properties. The thin layer of soil covering the surface of the earth represents the difference between survival and extinction for most land-based life ${ }^{3}$.

\section{Material and Methods}

The different localities from Rajgurunagar (Khed) Tehsil such as Kadus, Bordara, Rajgurunagar (Khed), Peth, Kanhersar were selected for sampling the soil to identify the soil profile and nutrient status to screen the potential for sustainable land utilisation and to guide the farmers for soil quality improvement. As the Rajgurunagar

TABLE-2 : Water holding capacity

\begin{tabular}{c|l|c}
\hline Sr. & Location & $\begin{array}{c}\% \text { of water holding } \\
\text { capacity of soil }\end{array}$ \\
\hline 1 & Kadus & 64 \\
\hline 2 & Bordara & 67 \\
\hline 3 & Peth & 69 \\
\hline 4 & Rajgurunagar (Khed) & 63 \\
\hline 5 & Kanhersar & 65 \\
\hline
\end{tabular}

(Khed) is known for well irrigation so most people are dependent on agricultural based income. We have identified the status of soil and characterisations of soil for qualitative and quantitative level which have taken place. Soil productivity is usually defined by foresters as the ability of a soil to produce biomass per unit area per unit time $^{4}$. The relationship of crop with nutrients present within soil need to screen in order to find out the best solution for agriculture at Rajgurunagar (Khed) Tehsil. Soil depth, (SOM) soil organic matter and electrical conductivity were selected as properties most affected by soil degradation processes $^{1}$.

Soil organic matter is a most significant indicator of soil quality and productivity ${ }^{12}$. It is essential to find out- Nutrient availability, total organic carbon, texture, soil structure, $\mathrm{pH}$, electrical conductivity.

Random sampling on non-biased mode gives good view.

Physical properties which were considered such as:

1. Soil particle size- Soil particle size analysis was determined by pipette method ${ }^{5}$.

3 Soil samples each from 5 deferent localities (Bordara, Rajgurunagar (Khed), Kadus, Peth, Kanhersar) were collected and sieved properly to get uniform range of particles for particle size analysis.

2. Porosity of the soil from different localities was determined ${ }^{2}$.

Soil samples from 5 deferent localities (Bordara, Rajgurunagar (Khed), Kadus, Peth, Kanhersar) were collected to find out percentile porosity 
TABLE-3 : pH range different localities

\begin{tabular}{l|l|c}
\hline Sr. & Location & pH range \\
\hline 1 & Kadus & 6.9 \\
\hline 2 & Bordara & 7.0 \\
\hline 3 & Peth & 6.8 \\
\hline 4 & Rajgurunagar (Khed) & 7.1 \\
\hline 5 & Kanhersar & 6.8 \\
\hline
\end{tabular}

analysis on comparative basis.

3. Water holding capacity of soil: The water holding capacity depends on the overall texture of soil particles and porosity of soil ${ }^{15}$.

4. Soil organic content : The total amount of soil organic carbon decides the fertility factor of soil ${ }^{8}$.

\section{For studying chemical properties}

5. pH analysis of soil: Soil samples from 5 different localities (Bordara, Rajgurunagar (Khed), Kadus, Peth, Kanhersar were selected to get an idea of $\mathrm{pH}$ of soil. With the help of digital $\mathrm{pH}$ meter range of values obtained.

6. Electrical conductivity in relation with presence of salt in soil. The soil was mixed with distilled water and then measured for electrical conductivity with help of conductivity metre and TDS machine.

\section{Results and Conclusion}

\section{Soil particle size-}

Soil particle size showing considerable amount of larger particles, indicate poor soil quality and texture.

3 samples from each location were collected for better understanding. Results are indicated

The graphical representation of variation in soil particle size in different localities on an average scale, is showing the presence of maximum share of sandy particles, which result in bad water holding capacity.

\section{Porosity of the soil:}

By using a formula: Percentage Solid space $=100 \times$ Bulk density/Particle density.

The average percentage of porosity of soil from different localities indicates poor water holding capacity of the soil, which is affecting the growth of soil in semi arid region of Rajgurunagar (Khed) Tehsil.

\section{Water holding capacity of soil:}

Poor water holding capacity of soil is a result of cumulative effect of soil particle size and porosity. Only Peth and Kanhersar soil is good among the othe region soil of Tehsil.

\section{Soil organic carbon content:}

Results are indicating lesser amount of soil organic matter. Soil organic matter decides the fertility of soil and capacity of soil to sustain the vegetation ${ }^{19}$.

\section{5. pH analysis of soil:}

With the help of digital pH meter, the value obtained indicates that, the soil is variable in nature and exceeding the $7 \mathrm{pH}$ value. Such $\mathrm{pH}$ range affects the growth of plants by creating abiotic stress conditions.

6. Electrical conductivity in relation with presence of salt in soil

Electrical conductivity in relation with presence of salt in soil Oral Testing (Taste)

A sweet taste similar to the taste of cooking salt will often indicate $\mathrm{NaCl}$ salt content of over $0.5 \%$. A sharp tangy taste may indicate the presence of carbonate salts or sulphates. Tongue tasting is particularly useful when trying to establish whether damage to bituminous surface is due to salt attack.

\section{Field Determination of TDS}

The TDS of water samples may be determined in the field but it is usually better to do this under laboratory conditions because of the need for accurate weighting. A quick indication of levels of TDS can be obtained in the field by correlation with field EC, as described above, with upto $90 \%$ accuracy. Conductivity of the water mostly depends on presence of ions in it. By using conductivity meter it has been evaluated that presence of salts as parts per thousands (grams per litre ). Assessment of water quality is very important for knowing its suitability for different uses.

Higher TDS value indicates the quality of water. The water is rich with salts and not useful for drinking as well.

\section{Control measures:}

The Rajgurunagar (Khed) Tehsil is showing variable soil quality from poor soil quality to good soil quality. Vast area could come under agriculture if proper steps are taken forward. Growing industrialisation is affecting fertility of soil. Proper management is needed to overcome from future problems. For improvement of quality of soil, it is suggested to maximise the use of bio-fertilizers, especially solid formulate of BGA. To reduce salt content and to improve the soil quality, it is essential to plant as many trees and sustain them until condition comes under the control ${ }^{13}$. 


\section{References}

1. Arshad MA, Coen GM. Characterization of soil quality: Physical and chemical criteria. Am. J. Alter. Agric. 1992; $7: 25-31$.

2. Danielson RE, Sutherland PL. Porosity. In: A. Klute (Editor), Methods of Soil Analysis.Part 1.2nd edn.,Agron. Monogr. 9., ASA Madison, WI. 1986; pp. 443-46 I.

3. Doran JW, Sarrantonio M, Liebig M. Soil health and sustainability. In: Sparks, D.L. (Ed.), Advances in Agronomy, Vol. 56. Academic Press, San Diego. 1996; pp. 1-54

4. Ford DE. What do we need to know about forest productivity and how can we measure it? In: Ballard, R., Gessel, S.P. (Eds.), IUFRO Symposium on Forest Site and Continuous Productivity. USDA Forest Service, General Technical Report, PNW-163. 1983; pp. $2 \pm 12$.

5. Gee GW, Bauder JW. Particle-size analysis. In: A. Klute (Editor), Methods of SoilAnalysis. Part 1.2nd edn.,Agron. Monogr. 9, ASA Madison, WI. 1986; pp. 383-411.

6. Granatstein D, Bezdicek DF. The need for a soil quality index: Local and regional perspectives. Am. J. Alter. Agric. 1992; $7:$ 12-16.

7. Glanz JT. Saving Our Soil: Solutions for Sustaining Earth's Vital Resource. Johnson Books, Boulder, CO, USA. 1995.

8. Hudson BD. Soil organic matter and available water capacity.Journal of Soil and Water Conservation. 1994; 49(2), 189-194.

9. John W. Doran, Michael R. Zeiss. Soil health and sustainability: managing the biotic component of soil quality. Applied Soil Ecology. 2000; 15 : 3-11

10. Karlen DL, Mausbach MJ, Doran JW, Cline RG, Harris RF, Schuman GE. Soil quality: a concept, definition, and framework for evaluation. Soil Sci. Soc. Am. J. 1997; 61 : 4-10.

11. Lal R. Soil structure and sustainability. J. Sustainable Agric.1991; 1: 67-92.

12. Larson WE. Pierce FJ. Conservation and enhancement of soil quality. Evaluation for sustainable land management in the developing world.Vol. 2. IBSRAM Proc. 12, 2 Technical paper International board for soil research and management, Bangkok, Thailand. 1991; pp. 175-203.

13. Letey JOHN. Relationship between soil physical properties and crop production. In Advances in soil science (pp. 277-294).Springer New York. 1958.

14. National Research Council. Soil and Water Quality: An Agenda for Agriculture. National Academy Press, Washington, DC. 1993; p. 516.

15. Naeth MA, Bailey AW, Chanasyk DS, Pluth DJ. Water holding capacity of litter and soil organic matter in mixed prairie and fescue grassland ecosystems of Alberta. Journal of Range management. 1991; 13-17.

16. Papendick RI, Parr JF. Soil quality—The key to a sustainable agriculture. Am. J. Aller.Agric. 1992; 7: 2-3.

17. Sanders DW. International activities in assessing and monitoring soil degradation. Am. J.Alter. Agric. 1992; 7:17-24.

18. Warkentin BP. The changing concept of soil quality. J. Soil Water Conserv. 1995; 50:226-228.

19. Walkley AJ, Black IA. Estimation of soil organic carbon by the chromic acid titration method. Soil Sci. 1934; 37: 29-38. 